\title{
The Book Evaluation Procedure of Educational Materials in Zambia and its Challenges.
}

\author{
Jane Chavula \\ School of Education, \\ Department of Mathematics and Science \\ University of Zambia
}

\begin{abstract}
This paper highlights the evaluation procedure of materials at the Curriculum Development Centre in Zambia based on lived experiences and literature review on the subject. The quality of education in Zambia has been demonstrated by low student achievement in national and international assessments. Many factors have contributed to undermining the standards and quality of education and one of the factors is a dearth of textbooks and other learning materials. Hence there is dependence on the materials available, therefore there is need to ensure that the materials which are used in schools are of high standards. The Ministry of Education, Science, Vocational Training and Early Education came up with the Evaluation Criteria to make sure that once materials are evaluated and approved or recommended then, they will be good enough for use in Schools. But this is not the case as some of the books found in schools are of low standards and with shallow content. This is so because some good evaluators shun evaluating materials because the payments involved are not attractive. Some publishers supply materials which have mistakes instead of printing the final copy which was approved. Therefore, there is need to strengthen the evaluation committees and to make follow-ups over the final copies being published by the publishers.
\end{abstract}

Key words; Evaluation, Evaluation Criteria, Evaluator.

\section{INTRODUCTION}

Zambia's education system consists of Early Childhood Education (ECE), primary, secondary and tertiary levels. ECE provides education for children aged 3 to 6 years, while primary level runs from grades 1 to 7 for children aged 7 to 13 years. Secondary level runs from grade 8 to 12 (14-18 years old). Tertiary education level includes universities and college (Ministry of General Education, 2015)[4]. The Zambian Government places education at the centre of the development process. Over the years, many factors have contributed to undermining the standards and quality of education in Zambia of which one of the factors is the dearth of textbooks and other learning materials (Ministry of Education, 1996) [3]. The Educating Our Future document (1996) [3] states that quality education requires the availability and use of textbooks and other educational materials. Without these aids to the learning process, effective teaching and learning in the modern sense cannot take place.

Provision of quality education requires the supply of books, writing materials and educational items in sufficient quantity to meet the needs of all learners. The availability and use of these materials have a positive effect on the teaching and learning. In the absence of these materials, teaching and learning occur only with difficulty. In order to ensure that the materials being developed are of quality, the Ministry of General Education through the Curriculum Development Centre (CDC) has the Research and Evaluation faculty to monitor the education materials used in schools and to carry out research on the teaching and learning in schools. The Research and Evaluation (R\&E) faculty cuts across all other faculties which include; Languages, 
Natural Sciences, Combined Services and Social Sciences by working with the principals and specialists of all the faculties to ensure that materials being produced are of high quality.

According to the Ministry of Education Science Vocational Training and Early Education (Education, 2013) [6] in the past the Curriculum Development Centre, working on its own or with donor assistance, developed many textbooks used in Zambia's schools. However, with the adopting of democratic governance in 1991, textbook publishing was liberalized so that the private sector comes on board to participate in publishing school textbooks. In keeping with Zambia's espousal of an open and free market economy, the Ministry has seen the establishment of a fully liberalized school-book industry where publishers assume responsibility for book initiation, development, production and marketing (Ministry of Education, 1996) [3]. This has brought about a lot of dependence on the textbook on both the teacher and the learner and seems to have influenced self-esteem on both groups (Consortium for International Development Mississippi, 2009) [1]. All educational materials being developed, published or marketed for use in Zambia are submitted to Curriculum Development Centre for evaluation, recommendation and approval. Approved materials cover all the learning outcomes in the syllabus while recommended materials do not cover all the learning outcomes in the syllabus but has relevant content to supplement as other teaching and learning materials (Ministry of Education S. V., 2015)[8]. Course books are subjected to being approved while supplementary materials are subjected to being recommended. However, the supply of textbooks brought some challenges to the Ministry as the policy of liberalizing and decentralizing the procurement of textbooks was problematic (Ministry of General Education, 2016) [5]. According to the 2006 National Assessment Survey report, the majority of the pupils (59.9\% in English and 58.4\% in Mathematics) shared a textbook between 3 and 4 pupils. This meant that the targeted book/pupil ratio of two pupils per textbook was not achieved (Ministry of General Education, 2016) [5].

According to the Educational Statistical Bulletin (2015) [4] the total number of books in primary schools for English, mathematics, life skills and Zambian languages was 2, 924628 in 2015 against a total of 3, 215723 pupils national wide. The pupil-book ratio (PBR) calculated as total number of regular students divided by the total number of books, for English was at $\frac{1}{4}$, mathematics $\frac{1}{4}$ life skills $\frac{1}{8}$ and Zambian languages $\frac{1}{4}$. The overall PBR for the whole country was at $\frac{6}{7}$ for primary schools. For secondary schools the PBR for English was at $\frac{1}{4}$, mathematics $\frac{1}{6}$ life skills 0 and Zambian languages $\frac{1}{9}$. The PBR national wide was at $\frac{3}{5}$ as shown in the table below.

Table 1: Total Number of books and the Pupil-Book Ratio

\begin{tabular}{|c|c|c|c|c|c|c|c|}
\hline Subjects & English & Maths & $\begin{array}{l}\begin{array}{l}\text { Life } \\
\text { skills }\end{array} \\
\end{array}$ & $\begin{array}{l}\text { Zambian } \\
\text { Languages }\end{array}$ & $\begin{array}{l}\text { Total No. } \\
\text { of books }\end{array}$ & $\begin{array}{l}\text { Total No. } \\
\text { of pupils }\end{array}$ & $\begin{array}{l}\text { Overal } \\
\text { I PBR }\end{array}$ \\
\hline $\begin{array}{l}\text { Primary } \\
\text { PBR }\end{array}$ & $\begin{array}{c}871804 \\
\frac{1}{4}\end{array}$ & $\begin{array}{c}800120 \\
\frac{1}{4}\end{array}$ & $\begin{array}{c}403240 \\
\frac{1}{8}\end{array}$ & $\begin{array}{r}849464 \\
\frac{1}{4}\end{array}$ & 2,924628 & 3215723 & $\frac{6}{7}$ \\
\hline $\begin{array}{l}\text { Secondary } \\
\text { PBR }\end{array}$ & $\begin{array}{c}188473 \\
\frac{1}{4}\end{array}$ & $\begin{array}{c}127307 \\
\frac{1}{6}\end{array}$ & $\begin{array}{l}35822 \\
0\end{array}$ & $\begin{array}{r}88234 \\
\frac{1}{9}\end{array}$ & 439836 & 802341 & $\frac{3}{5}$ \\
\hline
\end{tabular}

Source: 2015 Educational Statistical Bulletin.

The table shows that there is need for books more especially at secondary level, particularly for life skills. The shortage of books continues to constrain the quality of education, thereby adversely affecting the educational outcomes. 


\section{IMPORTANCE OF TEXTBOOKS}

The Ministry of Education Science Vocational Training and Early Childhood Education (2014) [7] states that a textbook is a link between the intended curriculum and the implemented one. The text books for the Zambian school curriculum are important materials for embodying curriculum objectives, content, specific outcomes, skills and values in the syllabus. Textbooks are important to aid the teaching and learning for teachers and learners respectively. A textbook is one of the primary sources of teaching materials. Sidhu (2006) [10] states that a good textbook adds knowledge to the teacher to teach effectively with quality content. This is in line with (Kochhar, 2013) [2] who said that teachers mostly think that the use of textbooks is important. A textbook assist managing a lesson. It saves time, gives direction to lessons, guides discussion, facilitates in giving homework making teaching easier, better organized and more convenient. It is a core resource and source of supplementary material such that teachers report that they rely almost entirely on textbooks for their teaching (Park, 2006)[9].

Suitable materials enable pupils to acquire and apply knowledge, to learn at their own pace and to assess their own progress (Ministry of Education, 1996) [3]. Textbooks enable pupils to acquire the needed information speedily. The pupils can even work independently at the at revision stage. It helps pupils understand things completely at home from textbooks, even if on certain occasions class work brings only partial understanding (Sidhu, 2006)[10].

Looking at the importance of a textbook and its dependence on it for both the teacher and the learner, the material should be of good quality and outcome based according to the requirements of the syllabus. Therefore, it is important for all textbooks and learning materials used in schools to meet and exceed the National Curriculum Standards as set by the Ministry of Education.

\section{EVALUATION PROCEDURE}

According to the Ministry of Education, Science, Vocational Training and Early Education (2015)[8] evaluation of educational materials takes five trained evaluators in a particular field to look at each material as the Book Approval Committee. The publisher sends four copies of the book to be evaluated together with the evaluation fee. On receipt of material for evaluation, the research and evaluation faculty liaise with the relevant principal who selects three evaluators from the trained panel of subject evaluators. The evaluators are contacted formally in writing. Their identities are confidential and should are only known by Research and Evaluation faculty and relevant sections. They use a document known as Evaluation Criteria to assess the strengths of the materials. The evaluation criteria are also availed to the book authors, and publishers to follow when writing their materials. The educational materials for use in schools which must be evaluated, include books, maps, tablets, educational audios and videos just to mention a few. The evaluators are given a maximum of four weeks in which to submit approval reports. The evaluators basically concentrate on nine categories of the Evaluation Criteria specifications which are content, language, teaching methodology, cultural and crosscutting issues, activities, exercises and testing, layout, illustrations and continuous assessment and other supplementary materials submitted (Ministry of Education S. V., 2015) [8].

The content in the material is the type of knowledge, skills and values in a specific discipline prescribed for learners at a specific age and grade level. The coverage of the syllabus topics in the material is checked to make sure that all the intended outcomes are tackled in the material. The scope and sequence of the content is supposed to be in line with the requirements of the syllabus. The depth and appropriateness of material is supposed to be designed for a specific age or grade level and should ensure a well-arranged sequencing of the knowledge, skills and 
values. The evaluators also check the length of time indicated for learning the content and the correctness of the concepts and principles. The weighting for content carries $30 \%$.

The teaching methodology should provide teacher with variety of teaching methods which encourage learner centred methods of teaching. Usually in course books the teaching methodologies are mainly placed in the teachers' guide. The evaluators check to verify that the methodology provided in the material is clear and easily understood. The methodology should be suitable to the intended readership and the proposed teaching and learning materials should be in line with the available resources. The suggested methods of teaching should have a balance between theory and practice and there should be provision of remedial and revision work with adequate coverage of topics. The weighting for this is $20 \%$.

The language used in the material should be clear and precise. The material should have correct grammar and spellings. The introduction of new terms should be gradual and there should be consistency in using them. The occurrence or proportion of gender terms in the material should be almost equal. The glossary should be should be provided as it helps learners to understand new concepts used in the material. The weighting for this is $10 \%$.

The evaluators are also interested in challenges that affect a cross section of society which are known as cross cutting issues. These cross-cutting issues include HIV/AIDS, poverty, child abuse, drug and substance abuse, human rights, health and nutrition, reproductive health and sexuality, population and family life, life skills, gender sensitivity and environmental degradation. It is a requirement that there is representation of authentic life of Zambia in the material so that learners can relate the text with their daily lives. In addition to the above issues, the textbooks developed should be completely culturally sensitive and integrate life skills appropriate to the children of Zambia. The weighting for this is $10 \%$.

There should be enough activities in the material to allow the learners to learn easily. These should be from simple to complex following the blooms taxonomy raking. The activities are supposed to stimulate the learners and they are supposed to be relevant to real life situations. The weighting for this is $5 \%$.

A material should have enough exercises and tests for the learners to have individual assessments on what has been taught in a particular lesson. Exercises should encourage learners to learn more on their own and should be written from simple to complex to cater for all the different types of learners. Tests can be placed after a number of topics have been covered so as to assess the acquisition of the content by the learners. The weighting for this is $5 \%$.

The material should have a very good layout. The type face and font size should be appropriate for the grade level and the page organization should be checked to ensure that the illustrations are properly placed. The headings should be clear and the material should have uniform format throughout the chapters. The pages should be used adequately and the book should be durable and portable. The weighting for this is $5 \%$.

The material should have clear illustrations. There should be a balance between illustrations and the text. The illustrations should depict what the text says and this should help to say less in the text. The material should aid at bridging the gap in terms of presentation of male and female. The colour used in the material should be communicative according to the age of the intended readership. The weighting for this is $5 \%$. 
The Continuous Assessment in the material should help the teachers to gather information on different decisions on teaching and learning process. Thus, evaluators ensure that there are adequate questions on continuous assessment provided. These need to be relevant, suitable and valid in the material. The items in the continuous assessment should reflect on the three domains in learning which are; cognitive domain dealing with thinking; affective domain dealing with feelings and the psychomotor domain dealing with muscle movement. This should evenly be spread out to bring out intended outcomes based on curriculum. This should also take into the account the Blooms Taxonomy. The weighting for this is $5 \%$.

There are course books which are evaluated with supplementary materials such as graph papers, science apparatus, play materials, maps, globes, puppets, films, dictionaries, charts, general readers and many others. These items are also evaluated to ensure that they are suitable for the learners. The weighting for this is $5 \%$.

After each evaluator has gone through the material, the four evaluators discuss their findings about the material and come up with one evaluation report. This happens when the evaluators are in the same place. If they are in distant places the reports are sent to the faculty were a report is compiled by the book approval committee. It the book is not approved the authors are requested to work on the concerns and re-submit the book verification if the score is from 85 to 99 percent with minor corrections. If the material scores less than 85 percent but greater than 75 percent then it will not be approved but maybe considered to be a supplementary material. For the scores less than 75 percent it means the material has failed. The material has to be elevated to the intended status for use in the school. After the approval of the book the authors are requested submit the final book as a sample of the material which is supposed to be used in schools.

\section{CHALLENGES FACED BY THE FACULTY OF RESEARCH AND EVALUATION.}

The publishers usually deposit money in a government account for evaluation of the materials to take place. Once the books are enough for evaluation to take place the principal (R\&E) through the Chief Curriculum Specialist writes to the permanent secretary for the authorization of the money for evaluation purpose. This usually takes long, hence the delay for evaluation to take place. In some instances, publishers delay to pay evaluation fees on time hence delaying the evaluation process.

It has been observed that some books submitted for evaluation are not edited by the authors hence giving so much work to the evaluators as some authors expect the evaluators to edit their materials. Teachers and pupils have complained about the low standards of material being taken to schools. This is so because some approved books are printed wrongly when they are delivered to schools failing the whole evaluation process. Other challenges are as follows;

- The trained evaluators especially for local languages are not enough, therefore there is need to train more.

- The evaluation fee is not enough for some evaluators hence they shun to do the work.

- Evaluations which take place by sending of materials to evaluators out of town usually take longer and some reports go missing through postage. Evaluations which are done through workshops are more effective than the ones which are done in different places.

- Some textbook copies which go to the schools are not the final copies which were approved. 


\section{CONCLUSION AND RECOMMENDATIONS}

A lot of time should be put into the writing of the teaching and learning materials. A more realistic schedule must factor ample time for identification of authors, training, planning, writing, editing, pre-testing and post-testing, field testing, revision, evaluation and feedback, additional revision, final approval processes, printing, distribution and post monitoring and evaluation. It is the duty Curriculum Development Centre to provide a suitable curriculum for the learners and also provide appropriate materials to go with it. They need to provide quality course books and supplementary materials to aid the teaching and learning. The evaluation procedure should be followed by the evaluators to ensure that the quality of the materials being approved and recommended is according to the required standards.

The evaluation criteria should have independent specifics for each subject on the categories of content, language and teaching methodology. The science-based subjects should have detailed specifics to look at especially on the content to suit the requirements of teaching science through inquiry. This will set as a guide to the book writers to write materials in a scientific way to help learners develop scientific inquiry skills through good questioning and using real life situation-oriented tasks.

The government should improve and increase the funding on evaluation of educational materials. The composition of the evaluation committees should be revised to ensure that only credible and experienced subject practising teachers; specialist and standard officers sit on book evaluation committees to avoid approving books with a lot of mistakes. Follow-ups should be made to make sure that the final books printed by the publishers are the exact copies which were approved or recommended. Subject specialists should work closely with the publishers to ensure that the concerns raised by the teachers are attended to and the books are revised accordingly. The research and evaluation faculty human resource needs to be beefed up for better management of activities as they are always overwhelmed with work.

\section{References}

Consortium Development, Mississippi. (2009). Textbooks and Learning Materials Program Zambia. Washington DC: African Education Initiative.

Kochhar, S. K. (2013). Methods and Techniques of Teaching. New Delhi: Sterling Publishers.

Ministry of Education. (1996). Educating Our Future. Lusaka: MOE.

Ministry of Education. (2015). Educational Statistical Bulletin. Lusaka: MoGE.

Ministry of Education. (2016). Educational Sector National Implementation Framework III 2011-2015. Luasaka: MoGE.

Ministry of Education, Science, Vocational Training and Early Education. (2013). Zambia Education Curriculum Framework. Lusaka: CDC.

Ministry of Education, Science, Vocational Training and Early Education. (2014). Lets Do Kyozai. Lusaka: JICA.

Ministry of Education, Science, Vocational Training and Early Education. (2015). Evaluation Criteria. Lusaka: Curriculum Development Centre.

Park, D.-Y. (2006). Curriculum Reform Movement in the US - Science Education. Pacific Ram Conference on Education, (pp. 1-20). Hokkaido: Hokkaido University of Education.

Sidhu, K. S. (2006). The Teaching of Mathematics. New Delhi: Sterling Publishers. 